\title{
Factors affecting success and abstinence within a smoking cessation clinic: A one-year follow-up study in Turkey
}

\author{
Ayse D. Esen', Yuksel Soylem', Secil Arica', Gulten Belgin', Nadire Gonultas ${ }^{1}$
}

\begin{abstract}
INTRODUCTION Successful smoking cessation requires personal, environmental and pharmacological support. In our clinic, pharmacological treatment lasts up to three months. In this study, we aimed to investigate smoking cessation rates, the effects of follow-up visits and pharmacological therapies on smoking cessation in our smoking cessation clinic for one year.

METHODS Our study included 505 patient files that were randomly selected from the 5271 patients who were admitted to our outpatient clinic for smoking cessation in 2015-2016 and at least one year has passed from treatment initiation. Patients, who agreed to participate in this study, provided information on their smoking cessation status, treatment duration and drug side effects. Data were recorded on electronic media for statistical analysis. Significance was evaluated at $\mathrm{p}<0.05$. RESULTS Our study was conducted on 505 patients that were randomly selected, $309(61.2 \%)$ males and $196(38.8 \%)$ females. The mean age was $38.9 \pm 10.3$ years. There were 313 (61.9\%) participants who stopped smoking after treatment and $229(45.3 \%)$ were not smoking currently. The smoking cessation rate of males $(57.9 \%)$ was significantly lower than that of females $(68.4 \%)(\mathrm{p}=0.019)$. The rate of relapse of males $(12.9 \%)$ was significantly lower than that of females $(20.9 \%)$ $(\mathrm{p}=0.017)$. Side effects occurred in $68(13.5 \%)$ patients, 32 taking varenicline and 36 taking bupropion.

CONCLUSIONS In our study, $45.3 \%$ of the patients had stopped smoking after one year. Smoking cessation rates were higher in the early stages of treatment than at late periods. Approximately half of the participants had never attended follow-up visits. Due to the low number of follow-up visits, both pharmacological treatment and motivational support were insufficient for effective smoking cessation therapy.
\end{abstract}

\section{INTRODUCTION}

Tobacco use is the leading single preventable cause of death worldwide, killing over 7 million people each year. Tobacco Control Framework Convention (FCTC), the first international agreement on the fight against tobacco, was adopted by the World Health Organization's 56th World Health Assembly on 21 May 2003. It is almost a decade since WHO introduced 6 MPOWER measures in 2007 to help countries implement the Framework Convention on Tobacco Control; only 42 countries were protected

\section{AFFILIATION}

1 Department of Family Medicine, Okmeydani Training and Research

Hospital, Istanbul, Turkey

CORRESPONDENCE TO

Ayse D. Esen. Department of Family Medicine, Okmeydani Training and Research Hospital,

Okmeydani, Sisli, Istanbul, 34384,

Turkey. E-mail: didem_esen@ hotmail.com ORCID ID: https:// orcid.org/0000-0002-5475-353X

\section{KEYWORDS}

smoking cessation, smoking, Turkey, nicotine dependence, varenicline, bupropion

Received: 21 June 2020

Revised: 11 October 2020

Accepted: 14 November 2020 
Within the National Tobacco Control Program, smoking cessation outpatient clinics were established. In these clinics, psychological and social support is provided with appropriate medical treatment for the smokers ${ }^{3}$. Successful cessation of smoking requires personal, environmental and pharmacological support, along with knowledge of the factors that cause the use of tobacco ${ }^{4}$. In January 2015, our smoking cessation clinic started to admit patients. After examination, pharmacological treatment is initiated in appropriate cases, and cognitive behavior therapy is provided by experienced specialists. The pharmacological treatment lasts up to three months. Patient followup visits are performed at least once in the first 15 days, once a month up to three months, and once every three months until the end of one year. The psychologists also provide counselling and behavioral therapy during the first interview and follow-up. Patients are considered to have quit smoking if they do not smoke at the end of a year. Smoking cessation rates are determined monthly, quarterly and annually by smoking cessation polyclinics.

In our study, we aimed to investigate smoking cessation rates, the effects of follow-up and pharmacological treatments on smoking cessation in our smoking cessation clinic for at least one year.

\section{METHODS}

In the period 2015-2016, 5271 patients were admitted to our outpatient clinic for smoking cessation and at least one year has passed from treatment initiations. Our previously noted smoking cessation success rate was $45 \%$ at follow-up at one year in our smoking cessation clinic. According to our sample calculation, it was sufficient to include a minimum of 380 people from the patients who applied to our outpatient clinic with a 5\% margin of error at $95 \%$ confidence interval. A clinical study without a control group was conducted. Our study included 505 patient files that were randomly selected. Selection criteria of participants were: be available by phone, able to give reliable verbal information, and agree to participate in the study. Exclusion criteria were: people with less than a year after the beginning of treatment, aged $<18$ years, being unavailable by phone, cognitive impairment, psychotic illness, and inability to answer questions at interview. Ethics committee approval was obtained from the Ethics Committee of Okmeydani Training and Research Hospital (approval number 812).

The selected participants were reached using the phone number noted in the patient file. The participants were informed about this study, and their consent was obtained. If a participant could not be reached by phone or did not agree to participate in the study, the next patient file was considered.

Survey questions were asked to patients who agreed to participate in this study, such as their smoking cessation status if they started smoking again, how long they continued treatment and whether the drug has side effects. Alternative methods were not used to verify the former smoker status, for example, by asking a family member or a person who lived with the former smoker. Smokers who did not quit smoking and relapsed were classified as current smokers in our study.

Data were recorded on electronic media for statistical analysis, including age, gender, education level, Fagerström nicotine addiction test score, the number of cigarettes smoked per day, smoking years, and age of smoking initiation.

\section{Fagerström nicotine dependence test (FNDT)}

The Fagerström Nicotine Dependence Test (FNDT) developed from the Fagerström Tolerance Test (FTT) consists of six questions, and the answers are scored ${ }^{5}$. Fagerström nicotine addiction test scores are rated in three groups: low (0-3), medium (4-6), and high $(\geq 7)^{6}$. Turkish validity study of the Fagerström Nicotine Dependence Test was carried out by Uysal et al. ${ }^{7}$ and it was concluded that it could be used as a method of measurement in the evaluation of nicotine dependence in smoking cessation . The Fagerström nicotine addiction test is widely used in smoking cessation clinics. It is applied to every patient in our polyclinic and noted in patient files.

\section{Statistical analysis}

Conformity of parameters to the normal distribution was evaluated using the Shapiro Wilks test. In the evaluation of this study, data descriptive statistical methods (mean, standard deviation, frequency) and chi-squared test were used to compare qualitative data. Student's t-test was used to compare quantitative 
data. Significance was evaluated at $p<0.05$. For statistical analysis, IBM SPSS Statistics 22 program was used.

\section{RESULTS}

Our study was conducted among the 505 randomly selected patients, aged 18-65 years, 309 (61.2\%) males and 196 (38.8\%) females. The mean age was $38.9 \pm 10.3$ years; and 348 of the participants were married while 157 were single. The average number of cigarettes smoked per day was $27.0 \pm 10.2$, the mean age of starting smoking was $17.6 \pm 5.0$ years, the average number of smoking years was $20.9 \pm 10.3$ years, and average FNDT score was $6.5 \pm 2.2$. The findings showed that 305 patients were treated with bupropion, 196 with varenicline, and 4 with nicotine patches. Side effects occurred in 68 (13.5\%) patients, 32 taking varenicline and 36 taking bupropion. The treatment was changed in 30 patients due to side effects, the ineffectiveness of the drug, or the inability to find drugs. Of the patients, 253 (50.1\%) had never been to control, while $146(28.9 \%)$ came to control once, 59 (11.68\%) twice, 37 (7.3\%) three times, seven $(1.3 \%)$ four times, and three $(0.59 \%)$ came five times (Table 1).

In Table 2 it is shown that $313(61.9 \%)$ participants stopped smoking after treatment, and $84(26.8 \%)$ relapsed. After one year, 229 (45.3\%) participants were abstinent. Smoking cessation rate of males was significantly lower $(57.9 \%)$ than that of females $(68.4 \%)(p=0.019)$. The rate of quitting smoking (70.4\%) with a Fagerström score $<6$ was significantly higher than that $(58.0 \%)$ with a Fagerström score $\geq 6$ ( $p=0.008)$.

The smoking cessation rate $(67.9 \%)$ of the users who used varenicline was significantly higher than those who used bupropion $(58.4 \%)(\mathrm{p}=0.033)$.

The rate of relapse in males (12.9\%) was significantly

Table 1. Participant characteristics and smoking factors

$\begin{array}{llcc}\text { Characteristics and smoking factors } & \text { Categories } & n & \% \\ \text { Age (years) range, mean } \pm \text { SD } & & 18-65 & 38.85 \pm 10.31 \\ \text { Gender } & \text { Male } & 309 & 61.2 \\ & \text { Female } & 196 & 38.8 \\ \text { Marital status } & \text { Married } & 348 & 68.9 \\ & \text { Single } & 157 & 31.1 \\ \text { Education level } & \text { Primary school } & 184 & 36.4 \\ & \text { Secondary school } & 101 & 20.0 \\ & \text { High school } & 127 & 25.1 \\ \text { Presence of a smoker at home } & \text { University } & 18.4 \\ \text { Chronic disease } & \text { Yes } & 93 & 44.2 \\ & \text { No } & 223 & 55.8 \\ \text { Number of cigarettes smoked per day, range, } & \text { Yes } & 282 & 28.1 \\ \text { mean } \pm \text { SD } & \text { No } & 142 & 71.9 \\ \text { Initiation age of smoking, range, mean } \pm \text { SD } & & 363 & 26.98 \pm 10.2 \\ \text { Smoking years, range, mean } \pm \text { SD } & & 7-100 & 17.57 \pm 4.99 \\ \text { Fagerström score, range, mean } \pm \text { SD } & & & 20.86 \pm 10.29 \\ \text { Fagerström score } & <6 & 7-48 & 6.49 \pm 2.16 \\ \text { Treatments } & \geq 6 & 1-57 & 32.1 \\ & \text { Varenicline } & 2-10 & 67.9 \\ \text { Side effects } & \text { Bupropion } & 162 & 38.8 \\ & \text { Nicotine replacement } & 343 & 60.4 \\ & \text { Yes } & 196 & 0.8 \\ & \text { No } & 305 & 13.5 \\ & & 4 & 86.5 \\ & & 68 & \text { Continued }\end{array}$


Table 1. Continued

\begin{tabular}{|c|c|c|c|}
\hline Characteristics and smoking factors & Categories & $n$ & $\%$ \\
\hline \multirow[t]{2}{*}{ Changing the treatment } & Yes & 30 & 5.9 \\
\hline & \multirow[t]{4}{*}{ No } & 475 & 94.1 \\
\hline Duration of treatment (days), range, mean $\pm S D$ & & $0-90$ & $44.29 \pm 23.82$ \\
\hline Number of controls, range, mean \pm SD & & $0-5$ & $0.83 \pm 1.05$ \\
\hline \multirow[t]{7}{*}{$\begin{array}{l}\text { Reason for not coming to polyclinic control } \\
(n=444)\end{array}$} & & & \\
\hline & Lack of time & 250 & 56.3 \\
\hline & Couldn't find drug & 22 & 5.0 \\
\hline & Drug side effects & 33 & 7.4 \\
\hline & Drug was not effective & 33 & 7.4 \\
\hline & Could not use the drug regularly & 94 & 21.2 \\
\hline & Other & 12 & 2.7 \\
\hline \multirow[t]{2}{*}{ Quit smoking } & Yes & 313 & 62.0 \\
\hline & No & 192 & 38.0 \\
\hline \multirow[t]{2}{*}{ Current smoking } & No & 229 & 45.3 \\
\hline & Yes & 276 & 54.7 \\
\hline \multirow[t]{5}{*}{ Reason for re-starting smoking $(n=84)$} & Stressful incident & 8 & 9.5 \\
\hline & General stress & 12 & 14.3 \\
\hline & Environmental impact & 10 & 11.9 \\
\hline & Inability of continuing the treatment & 35 & 41.7 \\
\hline & Lack of motivation & 19 & 22.6 \\
\hline \multirow[t]{2}{*}{ Relapses $(n=313)$} & Yes & 84 & 26.8 \\
\hline & No & 229 & 73.2 \\
\hline
\end{tabular}

Table 2. Assessment of smoking cessation according to gender, presence of chronic disease, presence of a smoker at home, Fagerström score and treatments

\begin{tabular}{llrrr} 
Variable & Categories & \multicolumn{2}{c}{ Quit smoking } & $p$ \\
& & Yes & No & \\
& & $n(\%)$ & $n(\%)$ & \\
Gender & Male & $179(57.9)$ & $130(42.1)$ & ${ }^{*} 0.019$ \\
& Female & $134(68.4)$ & $62(31.6)$ & \\
Chronic disease & Yes & $95(66.9)$ & $47(33.1)$ & 0.154 \\
& No & $218(60.1)$ & $145(39.9)$ & \\
Presence of a & Yes & $144(64.6)$ & $79(35.4)$ & 0.286 \\
smoker at home & & $169(59.9)$ & $113(40.1)$ & \\
& No & $114(70.4)$ & $48(29.6)$ & ${ }^{*} 0.008$ \\
Fagerström score & $<6$ & $199(58.0)$ & $144(42.0)$ & \\
& $\geq 6$ & $133(67.9)$ & $63(32.1)$ & ${ }^{*} 0.033$ \\
Treatments & Varenicline & & \\
& Bupropion & $178(58.4)$ & $127(41.6)$ &
\end{tabular}

Chi-squared test, ${ }^{*} p<0.05$. lower than in females $(20.9 \%)(p=0.017)$. There was no statistically significant difference in quitting smoking between the mean age groups. There was no statistically significant difference in relapsing between the mean age groups $(\mathrm{p}>0.05)$ (Table 3$)$. After one year, $43.4 \%$ of males and $48.5 \%$ of females were current smokers, and there was no statistically significant difference between the two groups ( $\mathrm{p}>0.05$ ) (Table 4).

Of the patients, $47.9 \%$ with chronic disease and $44.4 \%$ of those without chronic diseases were current smokers, and there was no statistically significant difference between the two groups $(\mathrm{p}>0.05)$ (Table $4)$. In all, $45.7 \%$ of patients who smoke at home and $45 \%$ of non-smokers at home were currently smoking, and there was no statistically significant difference between them ( $\mathrm{p}>0.05$ ) (Table 4).

Current smokers (54.3\%) with Fagerström scores $<6$ were found to be statistically significantly more (41.1\%) than current smokers with Fagerström 
scores $\geq 6(p=0.005)$ (Table 4). Current smokers were $47.4 \%$ of the users of varenicline and $44.3 \%$ of those using bupropion, and there was no statistically significant difference between the two groups ( $>>0.05)$ (Table 4).

Table 3. Evaluation of smoking relapse according to gender, presence of chronic disease, presence of smokers in the house, Fagerström score and treatments

\begin{tabular}{llccc} 
Variable & Categories & \multicolumn{2}{c}{ Smoking relapse } & $p$ \\
& & \multicolumn{2}{c}{ Yes } & No \\
& & $n(\%)$ & $n(\%)$ & \\
Gender & Male & $40(12.9)$ & $269(87.1)$ & ${ }^{*} 0.017$ \\
& Female & $41(20.9)$ & $155(79.1)$ & \\
Chronic disease & Yes & $26(18.3)$ & $116(81.7)$ & 0.385 \\
& No & $55(15.2)$ & $308(84.8)$ & \\
Presence of a & Yes & $42(18.8)$ & $181(81.2)$ & 0.128 \\
smoker at home & & & & \\
& No & $39(13.8)$ & $243(86.2)$ & \\
Fagerström score & $<6$ & $29(17.9)$ & $133(82.1)$ & 0.433 \\
& $\geq 6$ & $52(15.2)$ & $291(84.8)$ & \\
Treatments & Varenicline & $39(19.9)$ & $157(80.1)$ & 0.054 \\
& Bupropion & $41(13.4)$ & $264(86.6)$ &
\end{tabular}

Chi-squared test, ${ }^{*} \mathrm{p}<0.05$.

Table 4. Evaluation of smoking status according to gender, presence of chronic disease, presence of smoker at home, Fagerström score and treatments

\begin{tabular}{|c|c|c|c|c|}
\hline \multirow[t]{3}{*}{ Variable } & \multirow[t]{3}{*}{ Categories } & \multicolumn{2}{|c|}{$\begin{array}{l}\text { Current smokers } \\
\text { (who did not quit } \\
\text { smoking and } \\
\text { relapsed) }\end{array}$} & \multirow[t]{3}{*}{$p$} \\
\hline & & Yes & No & \\
\hline & & $n(\%)$ & $n(\%)$ & \\
\hline \multirow{2}{*}{ Gender } & Male & $134(43.4)$ & $175(56.6)$ & 0.262 \\
\hline & Female & 95 (48.5) & $101(51.5)$ & \\
\hline \multirow[t]{2}{*}{ Chronic disease } & Yes & 68 (47.9) & $74(52.1)$ & 0.473 \\
\hline & No & $161(44.4)$ & $202(55.6)$ & \\
\hline \multirow{2}{*}{$\begin{array}{l}\text { Presence of a } \\
\text { smoker at home }\end{array}$} & Yes & $102(45.7)$ & $121(54.3)$ & 0.875 \\
\hline & No & $127(45.0)$ & $155(55.0)$ & \\
\hline \multirow[t]{2}{*}{ Fagerström score } & $<6$ & $88(54.3)$ & $74(45.7)$ & $0.005^{*}$ \\
\hline & $\geq 6$ & $141(41.1)$ & $202(58.9)$ & \\
\hline \multirow[t]{2}{*}{ Treatments } & Varenicline & 93 (47.4) & $103(52.6)$ & 0.485 \\
\hline & Bupropion & 135 (44. 3) & $170(55.7)$ & \\
\hline
\end{tabular}

Chi-squared test, ${ }^{*} p<0.05$.

\section{DISCUSSION}

In our study, $45.3 \%$ of the patients who applied to our outpatient clinic stopped smoking after one year. The rate of the patients who quit smoking during the first year of treatment was $61.9 \%$ while $26.8 \%$ started smoking again. According to previous research, the success of smoking cessation at the end of the first year varies between $19-48 \%^{3,4,8-15}$. The variable ratios in these studies may depend on many factors. The success of smoking cessation differs in the early and late periods of treatment and quitting. Early success rates are observed higher than in late periods ${ }^{3,11,14}$.

The smoking cessation rate in men was lower than in women at the beginning of treatment; however, women were less likely to maintain smoking cessation behavior, and no differences in quitting smoking rates were observed between males and females at the end of the first year. Also, no difference in the success of smoking cessation was found between the age groups.

Although some studies show that males have a higher rate of success, other studies emphasize that age and gender have no effect on smoking cessation rates $^{3,16}$. Monso et al. ${ }^{17}$ reported that gender and age were related to smoking cessation rates, with higher smoking cessation rates in males and older patients ${ }^{17}$. In some studies, it has been reported that smoking cessation rates increase with age regardless of gender ${ }^{8,13,18,19}$. Studies that examined the effects of education level on smoking cessation found that it is higher in groups with high levels of education ${ }^{11,19-21}$; but in some studies there was no difference between education level groups ${ }^{4,8,14,17}$. Monso et al. ${ }^{17}$ found that socioeconomic factors, such as education level and employment status, did not influence smoking cessation. There are other studies that report that the level of education, occupation type and employment status are not related to smoking cessation success ${ }^{3}$. In our study, no difference was found between the education level groups in terms of smoking cessation success.

The presence of underlying smoking-related disease may have increased the smoking cessation rate. In one study, smoking cessation rates were significantly higher in the group that reported pathological findings on chest radiography ${ }^{16}$. Monso et al. ${ }^{17}$ reported that people with chronic respiratory and cardiac disease had lower rates of smoking 
cessation success; however, there was no evidence that other chronic diseases or a history of depression have a negative effect on smoking cessation. In a study investigating the success of smoking cessation in patients with chronic obstructive pulmonary disease (COPD), smoking cessation rate was $29 \%$ in the COPD group and $49 \%$ in the control group ${ }^{10}$. The presence of comorbid conditions, such as cardiovascular, pulmonary and psychiatric disorders, has not been shown to have a positive or negative effect on smoking cessation ${ }^{8,14,20}$. In our study, no difference in smoking cessation was observed between patients with and without comorbid chronic disease.

While in some studies, it was found that the number of cigarettes smoked daily was associated with smoking cessation success, some studies reported that the number of cigarettes smoked daily was not related to smoking cessation success ${ }^{3,18,20}$. Several studies have shown that patients with low nicotine dependence scores have higher smoking cessation success ${ }^{3,11,19,21}$, but in some studies there was no difference in nicotine dependence score among the groups who quit smoking and those that did not quit smoking ${ }^{14,20,22}$.

We found that smoking cessation rate at the beginning of treatment was higher in those with FNBT score $<6$, while smoking rates were found to be lower for FNBT scores $\geq 6$ in one year or longer. The cessation rates were higher in smokers with greater dependence, in contrast to those reported in the literature. The reason for this finding may be that smokers with high dependence were given drug therapies more than smokers with low dependence. Drug therapies may be more effective on smokers with higher dependence, especially in later follow-up periods.

There are studies showing that living with smokers in the same house reduces smoking cessation success and living with a partner who never smoked seems to be a factor that can prevent smoking relapse ${ }^{12,14}$. In the present study, living with smokers in the same house did not influence smoking cessation success.

Smoking cessation rates are, in principle, higher in the early stages than in the late period ${ }^{3,12}$. In the present study, the rate of those who started smoking again after giving up smoking for a certain period at the end of treatment was $26.8 \%$. Approximately half of the participants had never attended follow-up visits. Research in Turkey detected higher rates of quitting smoking in patients who attended in three months one or more follow-up sessions, and even higher for three or more follow-up sessions ${ }^{23}$. A recent international study reported smokers who had more than one smoking cessation follow-up visit or were seen by a physician had a higher success rate ${ }^{24}$. Research has noted that the use of pharmacotherapy for at least five weeks was associated with an increased smoking cessation rate ${ }^{15}$.

In a study, the smoking cessation rate was $63 \%$ in the first 15 days at the beginning of treatment, then decreased gradually in the $1 \mathrm{st}, 3 \mathrm{rd}$, 6 th and 12 th month to $23 \%$ by the end of one year ${ }^{13}$. In another study, relapse rates of $37.1 \%$ were found after one year ${ }^{25}$

In a study, patients who quit smoking for at least six months after treatment, stress was the most important factor in starting smoking again ${ }^{18,20}$. In another study, stress and excessive desire to smoke were the most common reasons for starting smoking again after quitting ${ }^{13}$. In a study, it was shown that polyclinic controls reduce the risk of relapse and that high relapses are associated with mental health problems and having a smoking partner ${ }^{12,26}$. In our study, the most common reason for relapse was the inability to continue treatment, and then the lack of motivation and general stress.

We found that smoking cessation rates at the beginning of treatment were significantly higher in patients using varenicline compared to those using bupropion, but in the late period, about a year after the treatment, there was no difference in the success of smoking cessation between the two drugs. Also, in relapses, no significant difference was found between the two drugs. There are studies showing the superiority of varenicline to bupropion, nicotine replacement therapy and placebo in smoking cessation $^{8,27-37}$. There are also studies showing that there is no difference in the success of smoking cessation among medical treatments ${ }^{14}$. In two studies, the rate of quitting treatment due to side effects was found to be $12.6-15.9 \%$ for bupropion and $10.5-14.3 \%$ for varenicline use at different $\operatorname{doses}^{34,35}$. In our study, the rate of total side effects was $13.5 \%$, in accordance with the literature. 


\section{Limitations}

There are limitations in our study. We did not verify that patients quit smoking by measuring carbon monoxide levels in exhaled air. We assumed that our patients' statements about quitting smoking were reliable.

\section{CONCLUSIONS}

In our study, $45.3 \%$ of the patients who applied to our outpatient clinic stopped smoking after one year. Smoking cessation rates were higher in the early stages of treatment than late periods related to the percentage of people who were successful in quitting smoking at the beginning of treatment, but smoking cessation behavior could not be sustained after the treatment in the first year or later. Approximately half of the participants had never come to follow-up visits. Due to the low number of outpatient controls, both pharmacological treatment and motivational support were insufficient for effective smoking cessation therapy. Smoking cessation success can be increased and the continuation of non-smoking behavior can be ensured by continuing pharmacological treatments for three months and encouraging patients to come to polyclinic control after the third and sixth months.

\section{REFERENCES}

1. World Health Organization. WHO report on the global tobacco epidemic 2017 Monitoring tobacco use and prevention policies. https://apps.who.int/iris/bitstream/ handle/10665/255874/9789241512824-eng.pdf; jsessionid=C90F9F931D44E21420DC03026B9D7286? sequence $=1$. Published July 19, 2017. Accessed May 6, 2020.

2. World Health Organization. WHO report on the global tobacco epidemic 2019. Tobacco control profilescountries, territories and areas. https://www.who.int/ teams/health-promotion/tobacco-control/who-reporton-the-global-tobacco-epidemic-2019. Published July 25, 2019. Accessed May 6, 2020.

3. Sağlam L. Investigation of the results of a smoking cessation clinic and the factors associated with success. Turk J Med Sci. 2012;42(3):515-522. doi:10.3906/sag1101-1452

4. Yaşar Z, Kar Kurt Ö, Talay F, Kargı A. One-Year Follow up Results of Smoking Cessation Outpatient Clinic: Factors Affecting The Cessation of Smoking. Eurasian J Pulmonol. 2014;16:99-104. doi:10.5152/ejp.2014.48295

5. Heatherton TF, Kozlowski LT, Frecker RC, Fagerström KO. The Fagerström Test for Nicotine Dependence: a revision of the Fagerström Tolerance Questionnaire. Br J Addict.
1991;86:1119-1127. doi:10.1111/j.1360-0443.1991.tb01879.x

6. Bozkurt N, Bozkurt Aİ. Assessment of the Fagerstrom Test for Nicotine Dependence (FTND) used in the determination of nicotine dependence and developing a new test for the nicotine dependence. Pamukkale Medical Journal. 2016;9(1):45-51. doi:10.5505/ptd.2016.65365

7. Uysal MA, Kadakal F, Karşidağ C, Bayram NG, Uysal O, Yilmaz V. Fagerström test fornicotine dependence: reliability in a Turkish sample and factor analysis. Tuberk Toraks. 2004;52:115-121. PMID:15241694.

8. Argüder E, Karalezli A, Hezer H, et al. Factors Affecting the Success of Smoking Cessation. Türk Toraks Derg. 2013;14:81-87.

9. Egici MT, Ozturk GZ, Bukhari MH, Toprak D. Smoking Cessation with Medication and Behaviour Therapy. Pak J Med Sci. 2017;33(6):1459-1462. doi:10.12669/pjms.336.13653

10. Solak ZA, Başoğlu OK, Erdinc E. Success of smoking cessation in patients with chronic obstructive pulmonary disease. Tuberg Toraks. 2006;54(1):43-50. PMID:16615017.

11. Peña P, Zagolin M, Acuña M, Navarrete S, Bustamante P, Canals A. Factores asociados con el éxito de la terapia antitabaco en pacientes tratados con vareniclina: 10 años de experiencia en un programa multidisciplinario [Factors associated with success of a smoking cessation program]. Rev Med Chil. 2016;144(8):965-971. doi:10.4067/S0034-98872016000800002

12. Van den Brand FA, Nagtzaam P, Nagelhout GE, Winkens B, van Schayck CP. The Association of Peer Smoking Behavior and Social Support with Quit Success in Employees Who Participated in a Smoking Cessation Intervention at the Workplace. Int J Environ Res Public Health. 2019;16(16):2831. doi:10.3390/ijerph16162831

13. Fidan F, Pala E, Ünlü M, Sezer M, Kara Z. Factors Affecting Smoking Cessation and Success Rates of The Treatment Methods Used. The Medical Journal of Kocatepe. 2005;6(3):27-34.

14. Kanatsız B, Başlılar Ş, Şaylan B, Albay A, Başat SU. Evaluation of the Factors Affecting Success Rate and Medical Treatments In Smoking Cessation. Euras J Fam Med. 2017;6(2):65-71.

15. Siahpush M, Shaikh RA, McCarthy M, Sikora Kessler A, Tibbits M, Singh GK. Association between duration of use of pharmacotherapy and smoking cessation: findings from a national survey. BMJ Open. 2015;5(1):e006229. doi:10.1136/bmjopen-2014-006229

16. Balbay Ö, Annakkaya AN, Aytar G, Bilgi C. The Results of Smoking Cessation Programmes in Chest Diseases Department of Duzce Medical Faculty. Düzce Tip Fakültesi Dergisi. 2003;3:10-14.

17. Monsó E, Campbell J, Tønnesen P, Gustavsson G, Morera J. Sociodemographic predictors of success in smoking intervention. Tob Control. 2001;10(2):165-169. doi:10.1136/tc.10.2.165 
18. Fernandez E, Garcia M, Schiaffino A, Borras JM, Nebot M, Segura A. Smoking initiation and cessation by gender and educational level in Catalonia, Spain. Prev Med. 2001;32(3):218-223. doi:10.1006/pmed.2000.0794

19. See JHJ, Yong TH, Poh SLK, Lum YC. Smoker motivations and predictors of smoking cessation: lessons from an inpatient smoking cessation programme. Singapore Med J. 2019;60(11):583-589. doi:10.11622/smedj.2019148

20. Şahbaz S, Kılınç O, Günay T, Ceylan E. The Effects of Smoking Properties and Demographic Properties on the Results of Smoking Cessation Therapy. Tur Toraks Derg. 2007;8(2):110-114.

21. Janson C, Kunzli N, de Marco R, Chinn S, Jarvis D, Svanes $\mathrm{C}$, et al. Changes in active and passive smoking in European Community Respiratory Health Survey. Eur Respir J. 2006;27(3):517-524. doi:10.1183/09031936.06.00106605

22. Örsel O, Örsel S, Alpar S, Uçar N, Firat Güven S, Şipit T, et al. The Effect of Nicotine Dependence Stages on Smoking Cessation Treatment Results. Solunum Hastalıkları. 2005;16:112-118.

23. Esmer B, Sengezer T, Aksu F, Özkara A, Aksu K. Clinical, sociodemographic and tobacco-use factors associated with smoking cessation rates at three years follow-up, Ankara, Turkey. Tob Prev Cessation. 2019;5(December):1-8. doi:10.18332/tpc/114082

24. Huang WH, Hsu HY, Chang BC, Chang FC. Factors Correlated with Success Rate of Outpatient Smoking Cessation Services in Taiwan. Int J Environ Res Public Health. 2018;15(6):1218. doi:10.3390/ijerph15061218

25. Chaiton M, Diemert L, Cohen JE, et al. Estimating the number of quit attempts it takes to quit smoking successfully in a longitudinal cohort of smokers. BMJ Open. 2016;6(6):e011045. doi:10.1136/ bmjopen-2016-011045

26. Hawkins J, Hollingworth W, Campbell R. Long-term smoking relapse: a study using the british household panel survey. Nicotine Tob Res. 2010;12(12):1228-1235. doi:10.1093/ntr/ntq175

27. Nides M, Glover ED, Reus VI, Christen AG, Make BJ, Billing CB, Williams KE. Varenicline Versus Bupropion SR or Placebo for Smoking Cessation: A Pooled Analysis. Am J Health Behav. 2008;32(6):664-675. doi:10.5993/AJHB.32.6.10

28. Cahill K, Stead LF, Lancaster T. Nicotine receptor partial agonists for smoking cessation. Cochrane Database Syst Rev. 2012;(4):CD006103. doi:10.1002/14651858.CD006103.pub6

29. Gray KM, Carpenter JM, Lewis AL, Klintworth EM, Upadhyaya HP. Varenicline versus Bupropion XL for Smoking Cessation in Older Adolescents: A Randomized, Double-Blind Pilot Trial. Nicotine Tob Res. 2012;14(2):234-239. doi:10.1093/ntr/ntr130

30. Garrison GD, Dugan SE. Varenicline: A First-Line Treatment Option for Smoking Cessation. Clin Ther. 2009;31(3):463-491. doi:10.1016/j.clinthera.2009.03.021

31. Cinciripini PM, Robinson JD, Karam-Hage M, et al. Effects of Varenicline and Bupropion Sustained-Release
Use Plus Intensive Smoking Cessation Counseling on Prolonged Abstinence From Smoking and on Depression, Negative Affect, and Other Symptoms of Nicotine Withdrawal. JAMA Psychiatry. 2013;70(5):522-533. doi:10.1001/jamapsychiatry.2013.678

32. West R, Baker CL, Joseph C. Cappelleri JC, Bushmakin AG. Effect of varenicline and bupropion SR on craving, nicotine withdrawal symptoms, and rewarding effects of smoking during a quit attempt. Psychopharmacology. 2008;197(3):371-377. doi:10.1007/s00213-007-1041-3

33. Wu P, Wilson K, Dimoulas P, Mills EJ. Effectiveness of smoking cessation therapies: a systematic review and meta-analysis. BMC Public Health. 2006;6(1):300. doi:10.1186/1471-2458-6-300

34. Jorenby DE, Hays JT, Rigotti NA, et al. Efficacy of Varenicline, an a4 32 Nicotinic Acetylcholine Receptor Partial Agonist, vs Placebo or Sustained-Release Bupropion for Smoking Cessation: A Randomized Controlled Trial. JAMA. 2006;296:56-63. doi:10.1001/jama.296.1.56

35. Nides M, Oncken C, Gonzales D, Rennard S, Watsky EJ, Anziano R, Reeves KR. Smoking cessation with varenicline, a selective alpha4beta2 nicotinic receptor partial agonist: results from a 7 -week, randomized, placebo- and bupropion-controlled trial with 1-year follow-up. Arch Intern Med. 2006;166(15):1561-1568. doi:10.1001/archinte.166.15.1561

36. Raich A, Pinet C, Mallbe M, et al. Multimodal treatment for smoking cessation with varenicline in alcoholic, methadone-maintained, and psychotic patients: A oneyear follow-up. Tob Induc Dis. 2018;16(December):1-11. doi:10.18332/tid/99541

37. Hyun S, Huh H, Kang NG. Effectiveness of auricular acupuncture combined with nicotine replacement therapy for smoking cessation. Tob Induc Dis. 2018;16(September):1-6. doi:10.18332/tid/94328

\section{ACKNOWLEDGEMENTS}

We thank Ebru Osmanoğlu for her help in statistical analysis and all participants of this study for their valuable contribution.

\section{CONFLICTS OF INTEREST}

The authors have completed and submitted the ICMJE Form for Disclosure of Potential Conflicts of Interest and none was reported.

\section{FUNDING}

There was no source of funding for this research.

\section{AUTHORS' CONTRIBUTIONS}

All authors have contributed to the work and approved the final version of the manuscript for publication. ADE, YS, SA, GB and NG were responsible for the study concept and design. SA contributed to data analysis. SA, $A D E$ and $Y S$ interpreted data, drafted the manuscript, and prepared the tools used in the data gathering. GB and NG had the responsibility of data gathering. $S A$ and $A D E$ revised the manuscript, and the whole process was under the supervision of SA, ADE and YS.

\section{PROVENANCE AND PEER REVIEW}

Not commissioned; externally peer reviewed. 